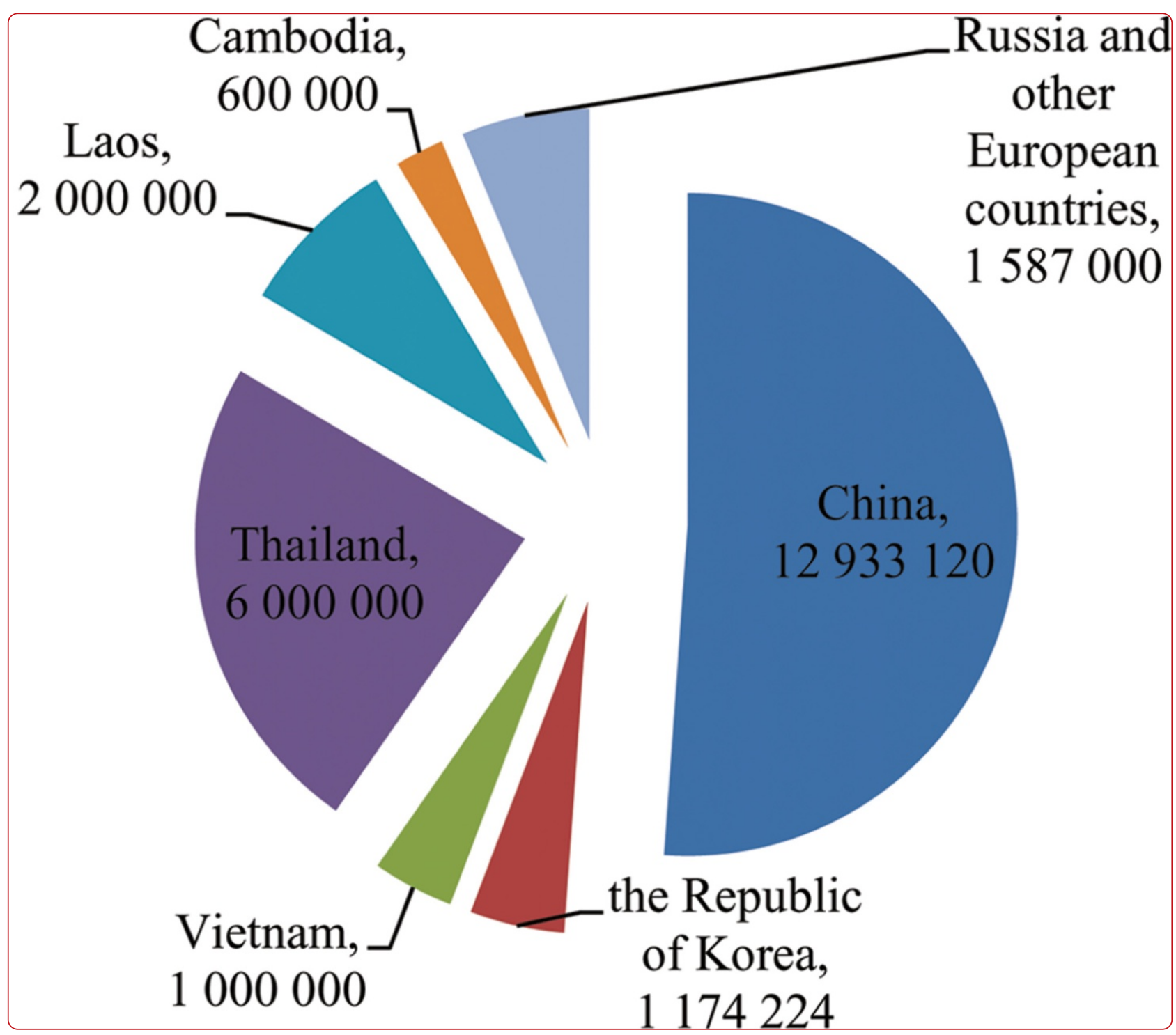

\title{
Time to tackle clonorchiasis in China
}

Qian et al. 


\title{
Time to tackle clonorchiasis in China
}

\author{
Men-Bao Qian ${ }^{1 *}$, Ying-Dan Chen ${ }^{1}$ and Fei Yan ${ }^{2}$
}

\begin{abstract}
Recent publication of the global epidemiology of clonorchiasis and its relationship with cholangiocarcinoma in the journal of Infectious Diseases of Poverty has stressed the importance of Clonorchis sinensis infection. To further demonstrate its threat on public health, especially in China, comparisons between clonorchiasis and hepatitis B are made in terms of epidemiology, clinical symptoms and carcinogenicity, disability, as well as changing trends. Furthermore, major problems and prioritized researches are argued, from basic biology to intervention. Imbalance between the majority of infected population and the minority of researches in China urges for more work from Chinese scientists and international cooperation.
\end{abstract}

Keywords: Clonorchis sinensis, Clonorchiasis, Hepatitis B virus, Liver cancer, Research

\section{Multilingual abstracts}

Please see Additional file 1 for translations of the abstract into the six official working languages of the United Nations.

\section{Background}

A review on the global epidemiology of clonorchiasis and its relationship with cholangiocarcinoma (CCA) was published in the journal of Infectious Diseases of Poverty on $25^{\text {th }}$ October 2012 [1]. A total of 15 million people are estimated to be infected with Clonorchis sinensis in East Asia and nearly 5,000 CCA cases attributed to this infection may occur annually in the coming decades. That article seeks to elucidate the situation and impact of clonorchiasis. However, some more deserve to be discussed, especially in China.

\section{Discussion}

\section{Comparisons between clonorchiasis and hepatitis B in China}

Clonorchiasis ranks among the top neglected tropical diseases [2]. Thus, comparing it with hepatitis B will promote revealing its threat on public health in China.

Firstly, most people infected with hepatitis B virus (HBV) distribute in China, and so do C. sinensis

\footnotetext{
*Correspondence: ahtlqmb-007@163.com

${ }^{1}$ National Institute of Parasitic Diseases, Chinese Center for Disease Control and Prevention; WHO Collaborative Center for Malaria, Schistosomiasis and Filariasis; Key Laboratory of Parasite and Vector Biology, Ministry of Health, Shanghai, People's Republic of China

Full list of author information is available at the end of the article
}

infections. A total population of 93 million is infected with HBV in China, which is about one quarter of the global number [3,4], while out of 15 million with $C$. sinensis infection globally, over $85 \%$ distributes in China (Figure 1A) [1]. Even after including another liver fluke infection, opisthorchiasis, the number in China is still over $50 \%$ (Figure 2B) $[1,5,6]$. Similar distribution characteristics in sexes and ages are shown in both infections, namely higher prevalence in males than in females and in adults than in children [1,7].

Secondly, as HBV mainly attacks the liver, C. sinensis infection also causes liver diseases, as well as biliary conditions. Although there are differences, some similarities may lead to misdiagnosis. Both may present nonspecific symptoms or signs, such as fatigue, loss of appetite, fever, nausea, abdominal pain, jaundice and hepatomegaly $[8,9]$. What is most similar is that both can cause liver cancer $[10,11]$. Hepatocellular carcinoma and CCA are the two most common types of liver cancer [12]. HBV is a definite carcinogen to hepatocellular carcinoma, while $C$. sinensis is the one to CCA $[10,11]$. Meta-analyses captured a general odds ratio of 15.6 for HBV infection in causing hepatocellular carcinoma [13], and 4.5 for C. sinensis infection in causing CCA [1]. Inflammation is the crucial factor in the carcinogenesis of both agents [10]. As the carcinogenicity is associated with the virus load in HBV [14], it is relevant to the infection intensity in Opisthorchis viverrini-homologous to C. sinensis [15]. 

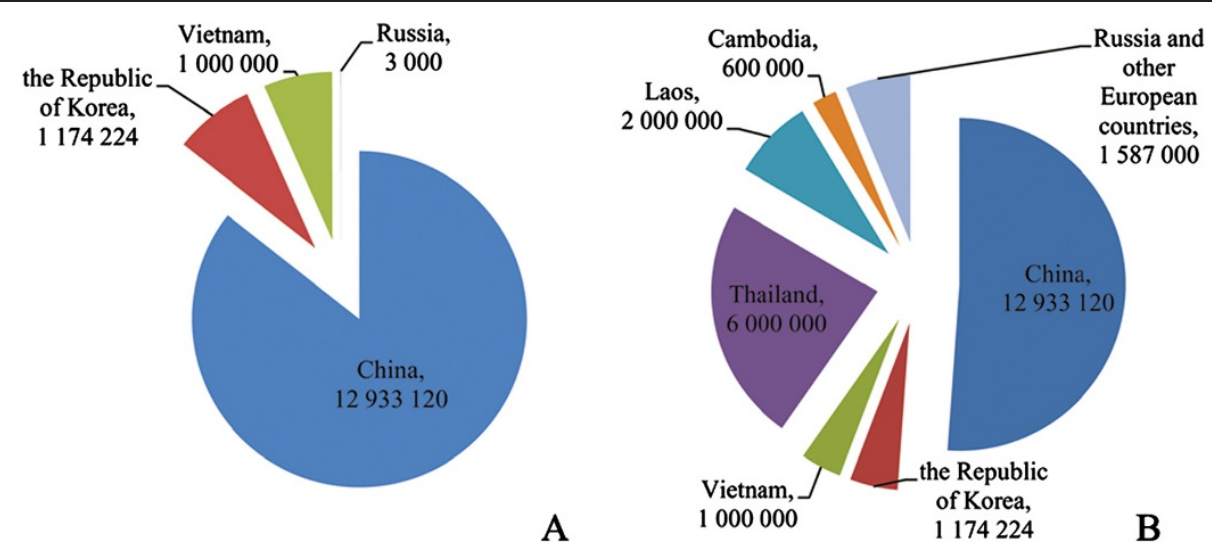

Figure 1 Population with liver fluke infections globally. A: Population with clonorchiasis. B: Population with clonorchiasis and opisthorchiasis.

Thirdly, both HBV and C. sinensis infections cause significant disability. An average disability weight of 0.075 in $C$. sinensis infection is captured through community survey and model simulation [16], which is unexpectedly the same as that in hepatitis B [17].

Nevertheless, different changing trends appear. Although there is no availability of treatment to completely clear HBV, efficient vaccine and great efforts contribute to its obvious decline, especially in China $[4,7,18]$. Even though specific drug, namely praziquantel, is available, neglect and re-infection cause the significant increase in clonorchiasis $[1,2]$.

Although there are fundamental differences in biology and some other aspects, comparisons above justify the public health importance of $C$. sinensis infection in China. Even though a relatively smaller population is infected with $C$. sinensis as compared with HBV nationally, the impact of clonorchiasis challenges hepatitis $B$ in major endemic areas, namely the east part of China $[1,19]$, where the former is becoming another killer of the liver and biliary health. The great success in controlling hepatitis B in China should provide valuable lessons for tackling clonorchiasis.

\section{More problems raised and more researches needed in China}

Recently, the Disease Reference Group on Helminth Infections (DRG4) established by the Special Programme for Research and Training in Tropical Diseases ranked prioritized researches for the control and elimination of major human helminthiases, including clonorchiasis [20]. Indeed, some have also been pointed out directly or indirectly in our former article.

Although three large-scale surveys involving clonorchiasis in China promote understanding the national situation and changes, epidemiology is only captured at the provincial level rather than at the county or lower level, which hampers the implementation of intervention measurements. Therefore, new methods, such as spatial techniques and modeling, deserve to be introduced to draw an epidemiological map for the disease [21,22]. Even though some epidemiological characteristics are known, social ecology and environmental determinants need to be elucidated further, such as the inherent drive for raw-fish-eating behavior, the cycle of infection-treatment-re-infection, factors involving in distributing and taking drug, roles of intermediate hosts, climate change [23], the property of zoonosis [24] and so on.

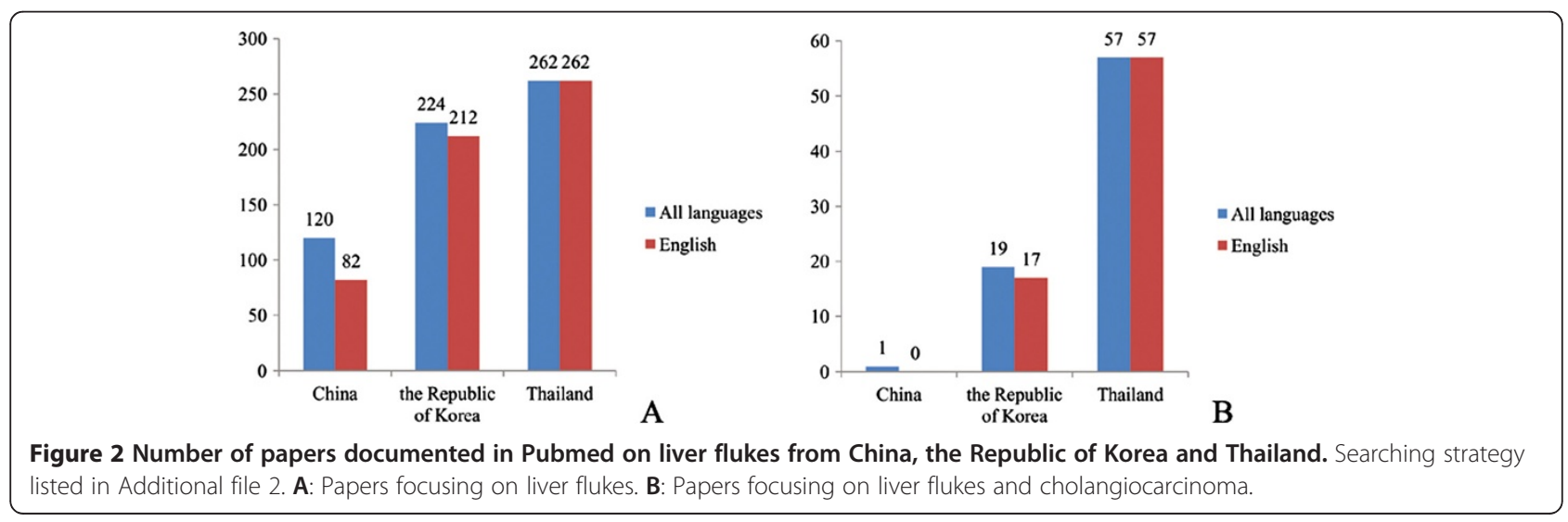


Whether other liver flukes and intestinal flukes are co-endemic in China challenges more accurate diagnosis, especially molecular methods $[1,25]$. Although two endemic zones have been classified [1] and some differences in biology have also been found [26], whether there exist differences in morbidity, especially in CCA, are also expected to be explored. It is already known that infection intensity is associated with carcinogenesis in O. viverrini infection [15], but corresponding studies in $C$. sinensis infection are not yet available, which causes unreasonably adopting the same OR in calculating CCA incidence in both sexes [1]. Furthermore, the impact of co-endemicity of $C$. sinensis and HBV infections on morbidity, especially on liver cancer in the east part of China, needs to be evaluated. Obviously, the establishment of tumor registry in China will promote related researches. Massive drug administration still counts on single drug, praziquantel [27], but no standardized principles of management are yet available. Additionally, tribendimidine, which shows promising efficiency against C. sinensis infection in vivo, in vitro, and in small field test, is expected to be further evaluated [28-30].

Even though most of the population infected with liver flukes distribute in China, corresponding researches are significantly less as compared with that in the Republic of Korea and Thailand, especially in CCA (Figure 2A and $2 \mathrm{~B}$, Additional file 2). The effort for controlling clonorchiasis in China will determine the global agenda for control and even elimination. Thus, more researches are anticipated from Chinese scientific workers. As it should be, international cooperation will be welcomed for tackling this problem [31].

\section{Summary}

The comparability between clonorchiasis and hepatitis B in epidemiology, clinical symptoms and carcinogenicity and disability, and contrast in changing trends, justify the threat of clonorchiasis and the urgency for intervention in China. Prioritized researches covering topics from basic biology to intervention are expected, which will benefit the control and even final elimination of clonorchiasis. However, the imbalance between the majority of infected population and the minority of researches in China draws more challenges. Thus, more efforts and outputs are expected from Chinese scientists, as well as international cooperation.

\section{Additional files}

Additional file 1: Multilingual abstracts in the six official working languages of the United Nations.

Additional file 2: Analysis on the number of papers documented in Pubmed on liver flukes from China, the Republic of Korea and Thailand.

\section{Competing interests}

The authors declare that they have no competing interests.

\section{Authors' contributions}

$M B Q, Y D C$ and FY discussed jointly. MBQ developed the first draft, and all authors read and approved the final manuscript.

\section{Acknowledgments}

The authors would like to thank Dr. Xiao-Nong Zhou for his critical advice and the reviewers for their valuable suggestions. This project is funded through a capacity building initiative for Ecohealth Research on Emerging Infectious Disease in Southeast Asia supported by the International Development Research Centre (IDRC), the Canadian International Development Agency (CIDA), and the Australian Agency for International Development (AusAID) in partnership with the Global Health Research Initiative (grant No. 105509-00001002-023), as well as supported by the National S \& T Major Program (grant No. 2008ZX10004-011), and by the National S \& T Supporting Project (grant No. 2007BAC03A02).

\section{Author details}

${ }^{1}$ National Institute of Parasitic Diseases, Chinese Center for Disease Control and Prevention; WHO Collaborative Center for Malaria, Schistosomiasis and Filariasis; Key Laboratory of Parasite and Vector Biology, Ministry of Health, Shanghai, People's Republic of China. ${ }^{2}$ School of Public Health, Fudan University, Shanghai, People's Republic of China.

Received: 10 December 2012 Accepted: 31 January 2013

Published: 19 February 2013

\section{References}

1. Qian MB, Chen YD, Liang S, Yang GJ, Zhou XN: The global epidemiology of clonorchiasis and its relation with cholangiocarcinoma. Infectious Diseases of Poverty 2012, 1:4.

2. First WHO report on neglected tropical diseases 2010: working to overcome the global impact of neglected tropical diseases. Available: http://www.who.int/ neglected_diseases/2010report/en/ Accessed 27 October 2010.

3. Lu FM, Zhuang H: Management of hepatitis B in China. Chin Med J (Engl) 2009, 122:3-4

4. World Health Organization: Hepatitis B vaccines. Wkly Epidemiol Rec 2009, 84:405-419.

5. WHO: Control of Foodborne Trematode Infections, WHO technical Report Series, Volume 849. Geneva: World Health Organization; 1995.

6. Sithithaworn $P$, Andrews RH, Nguyen VD, Wongsaroj T, Sinuon M, Odermatt P, Nawa Y, Liang S, Brindley PJ, Sripa B: The current status of opisthorchiasis and clonorchiasis in the Mekong Basin. Parasitol Int 2012, 61:10-16.

7. Liang X, Bi S, Yang W, Wang L, Cui G, Cui F, Zhang Y, Liu J, Gong X, Chen Y, Wang F, Zheng H, Wang F, Guo J, Jia Z, Ma J, Wang H, Luo H, Li L, Jin S, Hadler SC, Wang Y: Epidemiological serosurvey of hepatitis B in Chinadeclining HBV prevalence due to hepatitis B vaccination. Vaccine 2009, 27:6550-6557.

8. Keiser J, Utzinger J: Food-borne trematodiases. Clin Microbiol Rev 2009, 22:466-483.

9. Wilkins T, Zimmerman D, Schade RR: Hepatitis B: diagnosis and treatment. Am Fam Physician 2010, 81:965-972.

10. Bouvard V, Baan R, Straif K, Grosse Y, Secretan B, El Ghissassi F, BenbrahimTallaa L, Guha N, Freeman C, Galichet L, Cogliano V, WHO International Agency for Research on Cancer Monograph Working Group: A review of human carcinogens-Part B: biological agents. Lancet Oncol 2009, 10:321-322.

11. International Agency for Research on Cancer: A Review of Human Carcinogens Part B: Biological Agents. IARC monographs on the evaluation of carcinogenic risks to humans. Lyon: IARC; 2011.

12. Srivatanakul $P$, Sriplung $H$, Deerasamee S: Epidemiology of liver cancer: an overview. Asian Pac J Cancer Prev 2004, 5:118-125.

13. Shi J, Zhu L, Liu S, Xie WF: A meta-analysis of case-control studies on the combined effect of hepatitis $B$ and $C$ virus infections in causing hepatocellular carcinoma in China. Br J Cancer 2005, 92:607-612.

14. Chen CJ, Yang HI, Su J, Jen CL, You SL, Lu SN, Huang GT, Iloeje UH, REVEALHBV Study Group: Risk of hepatocellular carcinoma across a biological gradient of serum hepatitis B virus DNA level. JAMA 2006, 295:65-73. 
15. Haswell-Elkins MR, Mairiang E, Mairiang P, Chaiyakum J, Chamadol N, Loapaiboon V, Sithithaworn P, Elkins DB: Cross-sectional study of Opisthorchis viverrini infection and cholangiocarcinoma in communities within a highrisk area in northeast Thailand. Int I Cancer 1994, 59:505-509.

16. Qian MB, Chen YD, Fang YY, Xu LQ, Zhu TJ, Tan T, Zhou CH, Wang GF, Jia TW, Yang GJ, Zhou XN: Disability weight of Clonorchis sinensis infection: captured from community study and model simulation. PLoS Negl Trop Dis 2011, 5:e1377.

17. WHO Global burden of disease 2004 update: disability weights for diseases and conditions. Available: http://www.who.int/healthinfo/global_burden_disease/ GBD2004_DisabilityWeights.pdf Accessed 14 May 2010.

18. Zhou YH, Wu C, Zhuang H: Vaccination against hepatitis B: the Chinese experience. Chin Med J (Engl) 2009, 122:98-102.

19. Huang TR, Yu JH, Li JL, Zhang ZQ, Deng W, Zhang CY, Zhao SF: A crosssectional study on liver diseases in the rural residents in southern Guangxi, China. Zhonghua Yu Fang Yi Xue Za Zhi 2007, 41:123-126. in Chinese.

20. Utzinger J: A research and development agenda for the control and elimination of human helminthiases. PLoS Negl Trop Dis 2012, 6:e1646.

21. Zhou XN, Lv S, Yang GJ, Kristensen TK, Bergquist NR, Utzinger J, Malone JB: Spatial epidemiology in zoonotic parasitic diseases: insights gained at the 1st International Symposium on Geospatial Health in Lijiang, China, 2007. Parasit Vectors 2009, 2:10

22. Basáñez MG, McCarthy JS, French MD, Yang GJ, Walker M, Gambhir M, Prichard RK, Churcher TS: A research agenda for helminth diseases of humans: modelling for control and elimination. PLoS Negl Trop Dis 2012, 6:e1548.

23. Gazzinelli A, Correa-Oliveira R, Yang GJ, Boatin BA, Kloos H: A research agenda for helminth diseases of humans: social ecology, environmental determinants, and health systems. PLoS Negl Trop Dis 2012, 6:e1603.

24. Molyneux D, Hallaj Z, Keusch GT, McManus DP, Ngowi H, Cleaveland S, Ramos-Jimenez P, Gotuzzo E, Kar K, Sanchez A, Garba A, Carabin H, Bassili A, Chaignat CL, Meslin FX, Abushama HM, Willingham AL, Kioy D: Zoonoses and marginalised infectious diseases of poverty: where do we stand? Parasit Vectors 2011, 4:106.

25. McCarthy JS, Lustigman S, Yang GJ, Barakat RM, García HH, Sripa B, Willingham AL, Prichard RK, Basánez MG: A research agenda for helminth diseases of humans: diagnostics for control and elimination programmes. PLoS Negl Trop Dis 2012, 6:e1601.

26. Liu GH, Li B, Li JY, Song HQ, Lin RQ, Cai XQ, Zou FC, Yan HK, Yuan ZG, Zhou $\mathrm{DH}$, Zhu XQ: Genetic variation among Clonorchis sinensis isolates from different geographic regions in China revealed by sequence analyses of four mitochondrial genes. J Helminthol 2012, 86:479-484.

27. Prichard RK, Basáñez MG, Boatin BA, McCarthy JS, García HH, Yang GJ, Sripa $B$, Lustigman S: A research agenda for helminth diseases of humans: intervention for control and elimination. PLoS Neg/ Trop Dis 2012, 6:e1549.

28. Keiser J, Shu-Hua X, Chollet J, Tanner M, Utzinger J: Evaluation of the in vivo activity of tribendimidine against Schistosoma mansoni, Fasciola hepatica, Clonorchis sinensis, and Opisthorchis viverrini. Antimicrob Agents Chemother 2007, 51:1096-1098.

29. Xiao $\mathrm{SH}$, Xue J, Xu LL, Zheng $\mathrm{Q}$, Qiang $\mathrm{HQ}$, Zhang $\mathrm{YN}$ : The in vitro and in vivo effect of tribendimidine and its metabolites against Clonorchis sinensis. Parasitol Res 2009, 105:1497-1507.

30. Qian MB, Yap P, Yang YC, Liang H, Jiang ZH, Li W, Tan YG, Zhou H, Utzinger J, Zhou XN, Keiser J: Efficacy and Safety of Tribendimidine against Clonorchis sinensis. Clin Infect Dis 2013. in press; doi:10.1093/cid/cis1011.

31. Qian MB, Zhou XN, Fang YY, Liang S, Chen YD: Strengthening the research on clonorchiasis in China. Chin J Parasitol Parasit Dis 2011, 29:211-214. in Chinese.

doi:10.1186/2049-9957-2-4

Cite this article as: Oian et al: Time to tackle clonorchiasis in China. Infectious Diseases of poverty 2013 2:4.

\section{Submit your next manuscript to BioMed Central and take full advantage of:}

- Convenient online submission

- Thorough peer review

- No space constraints or color figure charges

- Immediate publication on acceptance

- Inclusion in PubMed, CAS, Scopus and Google Scholar

- Research which is freely available for redistribution

Submit your manuscript at www.biomedcentral.com/submit
C Biomed Central 